\title{
A Computational Study on the Variation of Bandgap Due to Native Defects in Non-Stoichiometric NiO and Pd, Pt Doping in Stoichiometric NiO
}

\author{
Srikanth Itapu ${ }^{1, *(\mathbb{C})}$, Vamsi Borra ${ }^{2}\left(\mathbb{D}\right.$ and Faramarz Mossayebi ${ }^{3 \oplus}$ \\ 1 Department of Electronics and Communication Engineering, CVR College of Engineering, \\ Hyderabad 501510, India \\ 2 Department of Applied Engineering and Technology, California University of Pennsylvania, \\ California, PA 15419, USA; borra@calu.edu \\ 3 Department of Electrical and Computer Engineering, Youngstown State University, \\ Youngstown, OH 44555, USA; fmossayebi@ysu.edu \\ * Correspondence: srikanth.itapu@rockets.utoledo.edu
}

Received: 21 October 2018; Accepted: 6 December 2018; Published: 7 December 2018

\begin{abstract}
This paper presents a computational study of non-stoichiometric nickel oxide in a 64-cell $\mathrm{NiO}$ system to model and validate localized heating effects due to nanosecond laser irradiation. Variation in the Bandgap of $\mathrm{NiO}$ is studied as a function of varying concentrations of native defects, ranging from 0 to $25 \%$. It is observed that there is a slight increase in the bandgap from $3.80 \mathrm{eV}$ for stoichiometric $\mathrm{NiO}$ to $3.86 \mathrm{eV}$ for $\mathrm{Ni}$-rich $\mathrm{NiO}$ and to $3.95 \mathrm{eV}$ for O-rich $\mathrm{NiO}$. It is hence deduced that the experimental laser irradiation leads to simultaneous reduction of $\mathrm{Ni}^{2+}$ ions and the oxidation of $\mathrm{NiO}$ as the number of laser pulses increase. As well, a detailed study on the effects of doping nickel family elements, i.e., palladium (Pd) and platinum (Pt), in stoichiometric $\mathrm{NiO}$ is presented. A bandgap decrease from $3.8 \mathrm{eV}$ for pure $\mathrm{NiO}$ to $2.5 \mathrm{eV}$ for Pd-doping and $2.0 \mathrm{eV}$ for Pt-doping for varying doping concentrations ranging from $0-25 \% \mathrm{Pd}, \mathrm{Pt}$, respectively, is observed.
\end{abstract}

Keywords: bandgap; dopants; nickel oxide; palladium; platinum

\section{Introduction}

Transition metal oxides (TMOs) establish an important section of semiconducting materials which exhibit a variety of electronic and magnetic properties that depend on the nature of their respective outer d-shell configurations [1]. Point defects in TM oxides, such as vacancies and interstitials, play a crucial role in determining the behavior of such oxides. Nickel Oxide $(\mathrm{NiO})$ is one such challenging transition metal oxide (TMO) that has been studied rigorously to establish an accurate theoretical analysis of its electronic structure [2-8]. NiO was first recognized as a Mott insulator in [2], where, until then, the perceptions of transition metal oxides were as conductors (according to band theory). It was initially suggested that band structures of such semiconductors with incomplete $\mathrm{d}$-bands cannot be explained in terms of potential barriers, instead, adding or removing of metal d-electrons could lead to the formation of discrete energy bands. Hence, the electrostatic interaction as well as the role of electron correlation was thoroughly discussed. In [3], the many-body effects in $\mathrm{NiO}$ measured by O-k edge XANES spectrum revealed the first experimental evidence that $\mathrm{NiO}$ was not a Mott type insulator with Hubbard gap $\mathrm{U}$ with a correlation gap between the initial state $\{\mathrm{E}[\mathrm{Ni}(3 \mathrm{~d} 8)]+\mathrm{E}[\mathrm{Ni}(3 \mathrm{~d} 8)]\}$ and the final state $\{\mathrm{E}[\mathrm{Ni}(3 \mathrm{~d} 7)]+\mathrm{E}[\mathrm{Ni}(3 \mathrm{~d} 9)]\}$, but it was a charge transfer insulator with a correlation gap between the initial state $\{\mathrm{E}[\mathrm{Ni}(3 \mathrm{~d} 8)]+\mathrm{E}[\mathrm{Ni}(3 \mathrm{~d} 8)]\}$ and the final state $\{\mathrm{E}[\mathrm{Ni}(3 \mathrm{~d} 8 \mathrm{O}(2 \mathrm{p} 5)]+\mathrm{E}[\mathrm{Ni}(3 \mathrm{~d} 9)]\}$ where the configuration $[\mathrm{Ni}(3 \mathrm{~d} 8 \mathrm{O}(2 \mathrm{p} 5)]$ is called $3 \mathrm{~d} 8 \mathrm{~L}$ where $\mathrm{L}$ is the ligand hole. This experimental evidence was strongly supported by researchers in [4], when defects 
in stoichiometric $\mathrm{NiO}$ were evaluated by observing the charge-transfer gap (i.e., observing changes in the relative configuration weight in $\mathrm{O}$ k-XANES).

Density functionaltheory (DFT) study on undoped $\mathrm{NiO}$ was first reported in detail in [1], wherein the electron correlations in the $3 \mathrm{~d}$ shell of metal ions in nickel oxide were computed using a combination of local spin density approximation (LSDA) and unrestricted Hartree-Fock approximation (U) techniques. This method was fit to calculate the total energy of crystalline nickel oxide and validate the obtained results by measuring the electron energy loss spectra. The local-density approximation (LDA) plus Hubbard model was implemented in [5] to compute the insulating antiferromagnetic ground state of $\mathrm{NiO}$ and its optical properties. It is observed that charge transfer was a result of the enhancement of $\mathrm{O} 2 \mathrm{p}$ character at the top of the valence state rather than Ni d-d LSDA-type band gap. In [6], an ab initio study of $\mathrm{NiO}$ at the $\mathrm{Pd}(100)$ surface was studied and observed that a $\mathrm{Ni}_{3} \mathrm{O}_{4}$ phase existed with rhombic distribution of $\mathrm{Ni}$ vacancies. A preferential formation due to surface reaction of $\mathrm{O}$ and $\mathrm{NiO}$ was shown to be thermodynamically possible along with some peculiar aspects resulting from a strong bond formation between $\mathrm{Ni}$ and $\mathrm{O}$ and $\mathrm{Pd}$ and $\mathrm{O}$ simultaneously. In [7], the magnetism of uniform porous $\mathrm{NiO}$ showed a distorted structure with an ordering temperature of $3 \mathrm{~K}$, and a paramagnetic ordering temperature of $13 \mathrm{~K}$. NiO clusters of less than $1 \mathrm{~nm}$ in size displayed ferromagnetic interactions. The stability and magnetism that are associated with vacancy in $\mathrm{NiO}$ are studied using GGA+U in [8]. The role of oxygen vacancies and mechanism of oxide reduction were dealt with in [9] and the electronic structure of oxygen and nickel vacancies at the surface of $\mathrm{NiO}$ (100) were investigated in [10] using hybrid DFT calculations. General gradient approximation (GGA) technique was used to study the defect formation energies under different conditions and inducted magnetism by vacancies in [8]. The results indicated that the dominant defect is Ni vacancy under oxygen-rich condition and the most suitable oxidation state varies with varying Fermi level.

The stoichiometric $\mathrm{NiO}$ is a Mott insulator with conductivity of $10^{-13} \mathrm{~S} / \mathrm{cm}$, while non-stoichiometric $\mathrm{NiO}_{x}$ is a wide-band-gap p-type semiconductor. The p-type conductivity of $\mathrm{NiO}_{x}$ originates from two positive charge compensation, which favors $\mathrm{Ni}^{2+}$ vacancies [11]. Several methods have been used for growing $\mathrm{NiO}$ films, including sputtering [12-15], e-beam evaporation [16,17], chemical and plasma-enhanced chemical vapor methods [18-20], pulsed laser deposition [21], and spray pyrolysis [22,23]. Among the above-mentioned techniques, sputtering is one of the preferred due to its industrial scalability, even though the composition of sputtered films varies slightly to significantly from equilibrium [24,25]. Lattice defects are not well-defined in $\mathrm{NiO}$ films with high oxygen content [26,27]. From [28,29], it is observed that high energy laser irradiation causes a change in the chemical composition as well as the electrical properties of $\mathrm{NiO}$, but a thorough computational analysis has not been presented to date. Because of its peculiar mechanism, nickel vacancy and/or interstitial oxygen are commonly used to describe the electrical properties of $\mathrm{NiO}$ films. To facilitate this study, density functional theory offers the right platform for defect analysis in terms of minimal errors, full convergence, and k-point integration.

Recent studies indicate an enormous work in doped $\mathrm{NiO}$ to enhance room temperature ferromagnetism for multiferroic devices [30], supercapacitor applications [31], and resistive switching [32]. Dopants, such $\mathrm{Cu}$ [32] and $\mathrm{Li}$ [33] enhance the p-type conductivity of $\mathrm{NiO}$ films and have been studied extensively, both theoretically and experimentally. Doping $\mathrm{NiO}$ with metals in the nickel family, i.e., Palladium (Pd) and Platinum (Pt), have gained attention, owing to their Electrochromic, supercapacitor, and gas-sensing applications and studied extensively experimentally [34-40], but no theoretical analysis has been investigated in knowing the vacancy and interstitial behavior in doped $\mathrm{NiO}$. In this paper, we also study the effect of doping Pd and Pton the bandgap of NiO by varying doping concentrations from 0 to $25 \%$ in a 32 atom $\mathrm{NiO}$.

\section{Computational Method}

All of the computations are performed based on the generalized gradient (GGA) and local density approximations (LDA) to DFT using the Vienna ab initio simulation package (VASP) [41-43]. 4 k-points in the irreducible part of the Brilliouin zone is a result of test of convergence in the 32-atom primitive 
cell. The single particle wave functions are expanded in a plane-wave basis using a $420 \mathrm{eV}$ energy cutoff for LDA and $460 \mathrm{eV}$ for GGA. Full relaxation of ions is performed for undoped $\mathrm{NiO}$ to find the minimum energy of each configuration. The absolute minimum in total energy was obtained by varying the lattice constant.

The density of states (DOS) calculations were performed using Methfessel-Paxton scheme for the energy [44]. Computations of dopants $(\mathrm{Pd}, \mathrm{Pt})$ were performed by substituting Ni positions in the 64 cell $\mathrm{NiO}$ with varying doping concentrations ranging from 0-25\%. Similarly, native defects $(\mathrm{Ni}, \mathrm{O})$ were introduced at interstitial sites in the 64 cell $\mathrm{NiO}$ with varying concentrations from $0-25 \%$, i.e., introducing 0 to $8 \mathrm{Ni}$ or $\mathrm{O}$ interstitials, respectively.

\section{Results and Discussion}

Pure nickel oxide belongs to the space group Fm-3m with the space number 225 . The primitive cell of $\mathrm{NiO}$ consists of a $\mathrm{Ni}_{16} \mathrm{O}_{16}$ unit of 32 atoms in a rock-salt structure. Positions of the 32-atom basis in this cell are obtained from international tables for crystallography [45]. The Ni atoms forming the fcc lattice occupy the Wyckoff position 4a. For a crystal lattice equivalent to an elastic medium, the change of the lattice constant is proportional to the concentration of the dopant and hence, Vegard's law is obeyed. Therefore, to examine the influence of doping on the lattice constant is examined, it is important to know the concentration of native defects.

\subsection{Density of States (DOS)-Excess Ni Occupying Interstitial Sites inNiO}

The GGA calculations imply that Ni interstitials play a dominating role under Ni-rich conditions, as depicted in Figure 1a-d, which is correlated with observed Ni deficiency and n-type behavior of $\mathrm{NiO}$. The results show $\mathrm{O}$ interstitials as unstable and that $\mathrm{O}$ vacancies are the lowest energy defects near the Fermi level. As a result, from [29], it is experimentally observed that Ni-rich NiO is typically n-type semiconductor. There is also a slight increase in the bandgap for increasing \% doping of excess of $\mathrm{Ni}$ in the $\mathrm{NiO}$ system (Figure $1 \mathrm{a}-\mathrm{d}$ ). Table 1 summarizes the extent of increase and it is comparable to the ellipsometric analysis that was established in [29].

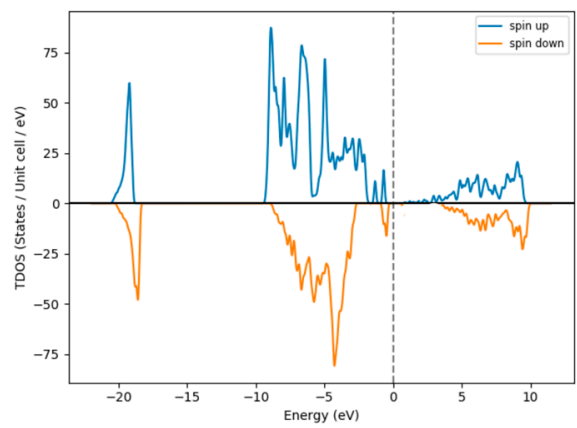

(a)

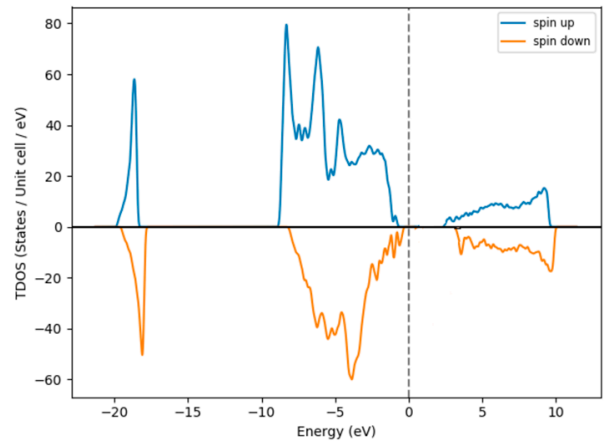

(c)

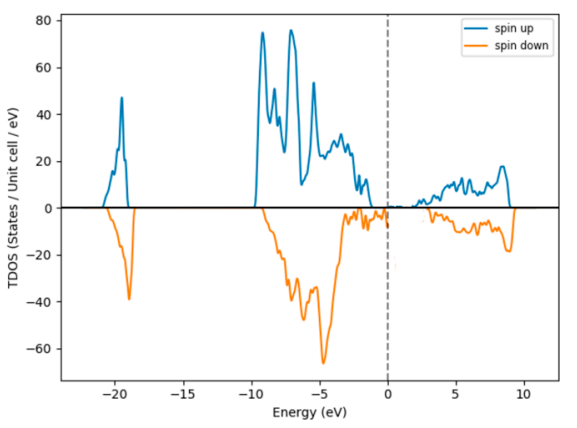

(b)

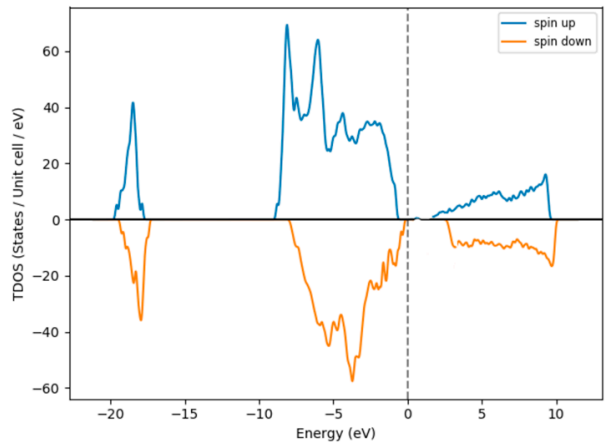

(d)

Figure 1. Density of States for excess $\mathrm{Ni}$ in $\mathrm{NiO}$ (a) $3 \%$, (b) $12 \%$, (c) $18 \%$, and (d) $25 \% \mathrm{Ni}$. 
Table 1. Bandgap of excess $\mathrm{Ni}$ in $\mathrm{NiO}$ with respect to \% doping.

\begin{tabular}{ccccc}
\hline \% Excess Ni & 3 & 12 & 18 & 25 \\
\hline Bandgap (eV) & $3.8 \pm 0.003$ & $3.83 \pm 0.005$ & $3.85 \pm 0.006$ & $3.86 \pm 0.008$ \\
\hline
\end{tabular}

\subsection{Density of States (DOS)—Excess O Occupying Interstitial Sites in NiO}

The computational analysis, as shown in Figure $2 \mathrm{a}-\mathrm{d}$, reveals that Ni vacancies dominate under excess $\mathrm{O}$ conditions, which is usually the case with sputtered $\mathrm{NiO}$ films being $\mathrm{Ni}$-deficient and p-type semiconducting in nature. From [29], it is observed experimentally that O-rich $\mathrm{NiO}$ is typically a p-type semiconductor. Table 2 depicts the increasing trend in bandgap with an increase in O concentration.

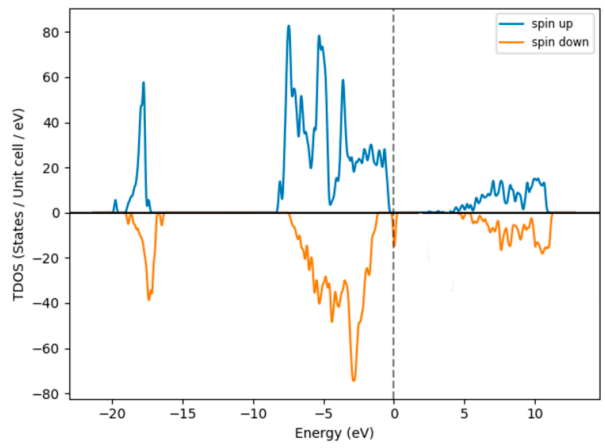

(a)

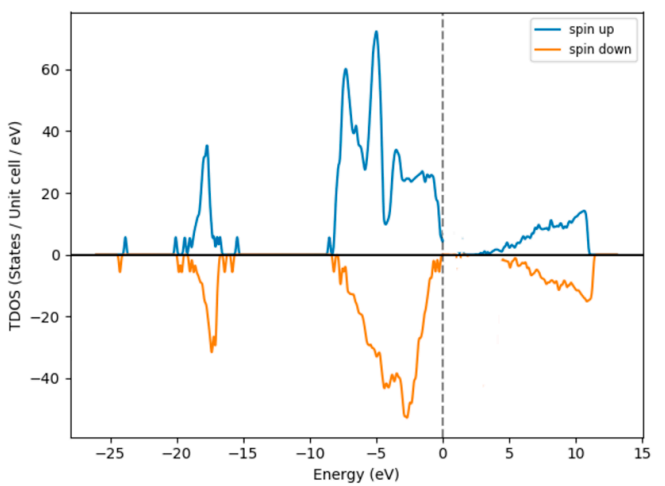

(c)

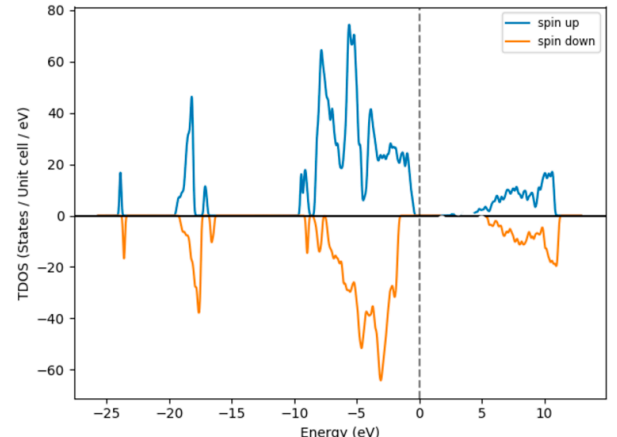

(b)

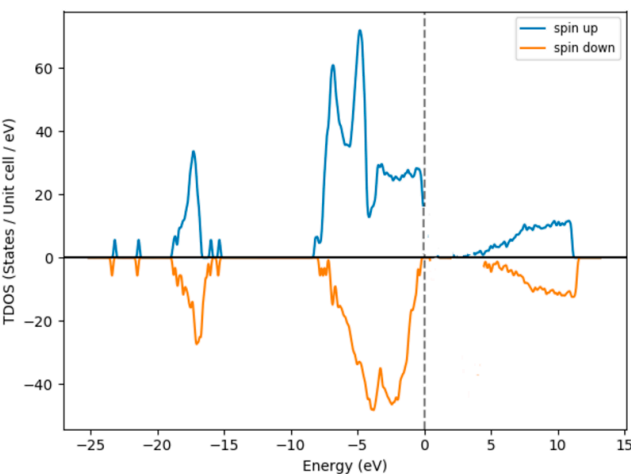

(d)

Figure 2. Density of States for excess $\mathrm{O}$ in $\mathrm{NiO}$ (a) $3 \%$, (b) $12 \%$, (c) $18 \%$, and (d) $25 \% \mathrm{O}$.

Table 2. Bandgap of excess $\mathrm{O}$ in $\mathrm{NiO}$ with respect to \% doping.

\begin{tabular}{ccccc}
\hline \% Excess $\mathbf{O}$ & 3 & 12 & 18 & 25 \\
\hline Bandgap (eV) & $3.80 \pm 0.02$ & $3.85 \pm 0.03$ & $3.90 \pm 0.03$ & $4.00 \pm 0.05$ \\
\hline
\end{tabular}

\subsection{Formation energies of oxides of $\mathrm{Pd}$ and $\mathrm{Pt}$}

The formation energies of the oxides of nickel family elements $(\mathrm{Pd}, \mathrm{Pt})$ are calculated as:

$$
E_{\text {form }}\left(M_{1-x} O_{x}\right)=\mu\left(M_{1-x} O_{x}\right)-(1-x) \mu_{M}-x \mu_{O}
$$

where $\mu\left(\mathrm{M}_{1-\mathrm{x}} \mathrm{O}_{\mathrm{x}}\right)$ is the energy per formula unit $\mathrm{M}_{1-\mathrm{x}} \mathrm{O}_{\mathrm{x}}(\mathrm{M}=\mathrm{Ni}, \mathrm{Pd}, \mathrm{Pt})$.

The formation energy of $\mathrm{PdO}$ is $2.52 \mathrm{eV}$ [46] and the formation energy of $\mathrm{PtO}$ is $-0.49 \mathrm{eV}$ [47].

Many approaches to fabricate $\mathrm{p}$-doped $\mathrm{NiO}$ are gaining attention among researchers. The nickel family elements $\mathrm{Pd}$ and $\mathrm{Pt}$ are studied as a single atom defect in the 32-cell NiO. The formation energies 
of Pd-/Pt-doped $\mathrm{NiO}$ as an uncharged defect at various substitutional sites were computed from Equation (2).

$$
\mathrm{E}_{\mathrm{form}}(\mathrm{D}, 0)=\mathrm{E}_{\text {def }}(\mathrm{D}, 0)-\mathrm{E}_{\text {pure }}(\mathrm{NiO})-(-1) \times\left[\left(\mu_{\text {pure }}(\mathrm{NiO})-\mu_{\mathrm{O}}\right]-(+1) \times \mu_{\mathrm{DMax}}\right.
$$

From Table 3, the defect formation energies for $\mathrm{Pd}_{\mathrm{Ni}}$ and $\mathrm{Pt}_{\mathrm{Ni}}$ reach minima at O-rich condition, which suggest that both $\mathrm{Pd}$-doped $\mathrm{NiO}$ and Pt-doped NiO show affinity to behave as p-type semiconductors.

Table 3. Formation energies of single $\mathrm{Pd}, \mathrm{Pt}$ atom defects (i.e., single atom in 32 atom $\mathrm{NiO}$ cell) as interstitials or substitutional defects in $\mathrm{NiO}$.

\begin{tabular}{ccc}
\hline Types of Defects & O-Rich Condition $\mathrm{E}_{\text {form }}(\mathbf{e V})$ & O-Poor Condition $\mathrm{E}_{\text {form }}(\mathbf{e V})$ \\
\hline $\mathrm{Pd}_{\mathrm{Ni}}$ & -0.33 & 1.54 \\
$\mathrm{Pt}_{\mathrm{Ni}}$ & -0.05 & 2.18 \\
$\mathrm{I}_{\mathrm{Pd}}$ & 2.55 & 2.55 \\
$\mathrm{I}_{\mathrm{Pt}}$ & 3.18 & 3.18 \\
\hline
\end{tabular}

\subsection{Density of States (DOS) - Pd as Dopant Occupying Interstitial Sites inNiO}

Figure 3a-dpresents DOS for 3\%-12\% doping of Pd in NiO. A band gap of $3.8 \mathrm{eV}$ is observed for $3 \% \mathrm{Pd}$ doping. As the doping increases, there is a decrease in the bandgap of Pd-doped $\mathrm{NiO}$ up to $12 \%$ doping. It is plausible to explain that the bandgap has a negligible effect on doping up to $12 \% \mathrm{Pd}$, because these $\mathrm{Pd}$ atoms occupy only interstitial sites in the 64-cell $\mathrm{NiO}$ system. Table 4 summarizes the bandgap versus \% doping in $\mathrm{Pd}-\mathrm{NiO}$ system.

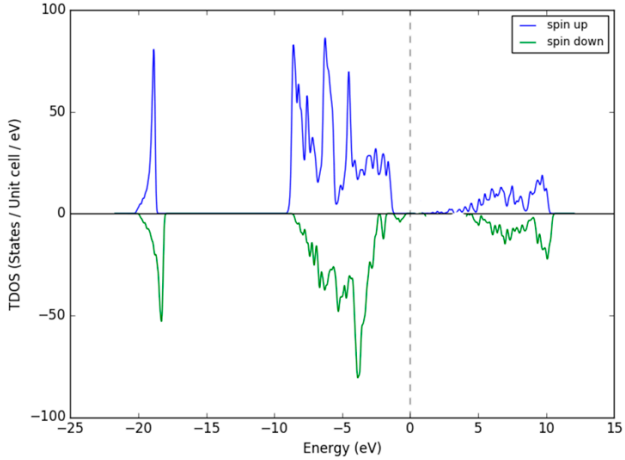

(a)

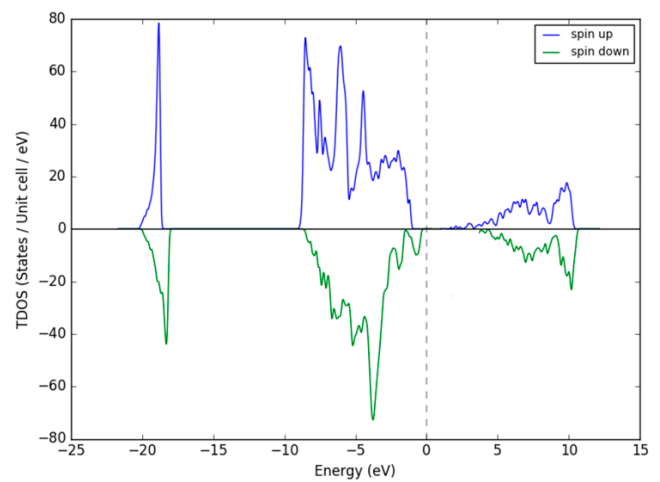

(c)

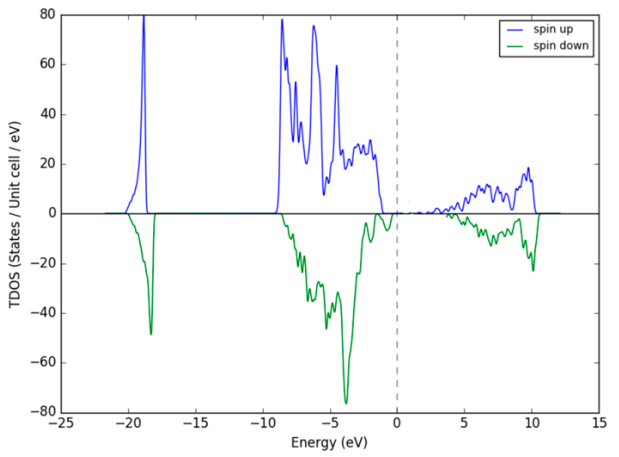

(b)

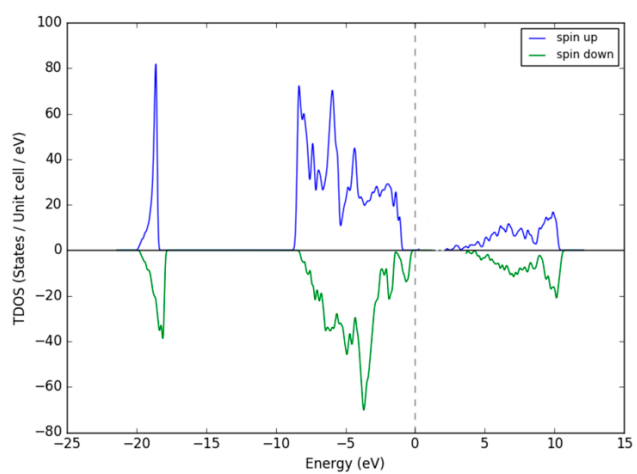

(d)

Figure 3. Density of States for Pd- doped $\mathrm{NiO}$ (a) $3 \%$ (b) $6 \%$ (c) $9 \%$, and (d) $12 \% \mathrm{Pd}$. 
Table 4. Bandgap of $\mathrm{Pd}$-doped $\mathrm{NiO}$ with respect to \% doping.

\begin{tabular}{ccccccccc}
\hline \% Pd doping & 3 & 6 & 9 & 12 & 15 & 18 & 21 & 25 \\
\hline Bandgap (eV) & $3.80 \pm 0.02$ & $3.75 \pm 0.08$ & $3.50 \pm 0.06$ & $3.20 \pm 0.04$ & $2.95 \pm 0.03$ & $2.80 \pm 0.04$ & $2.70 \pm 0.02$ & $2.50 \pm 0.02$ \\
\hline
\end{tabular}

For higher doping percentage of $\mathrm{Pd}$ in $\mathrm{NiO}$ (Figure 4a-d), there is a further decrease in the bandgap of $\mathrm{Pd}$ doped $\mathrm{NiO}$ from $2.95 \mathrm{eV}$ to $2.5 \mathrm{eV}$. This arises from the $\mathrm{Pd}^{2+}$ substituting $\mathrm{Ni}^{2+}$ sites, resulting in an increase in the lattice constant and overall volume of the cubic cell. $\mathrm{The}^{\mathrm{Pd}^{2+}}$ atoms reorganize and stabilize the $\mathrm{NiO}$ units with increase in dopant concentration. The nonstoichiometric phase of $\mathrm{NiO}_{x}$ goes through a phase of oxygen reduction (i.e., electrons), thus keeping the Fermi level that is close to the valence band [32]. Hence, it can be deduced that Pd-NiO is p-type in nature.

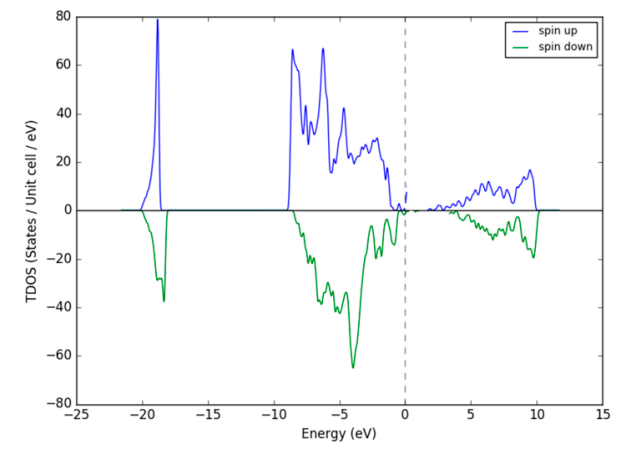

(a)

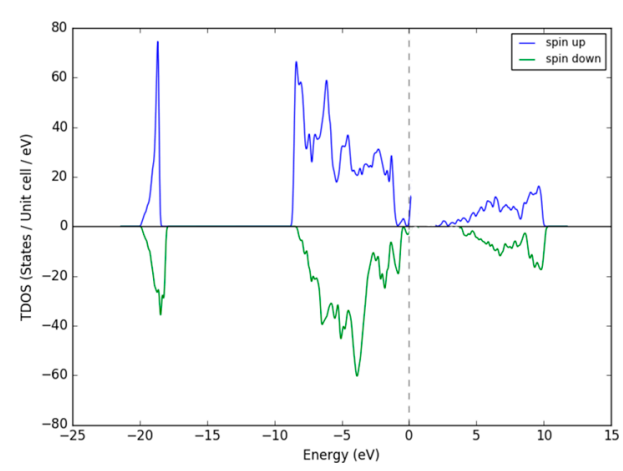

(c)

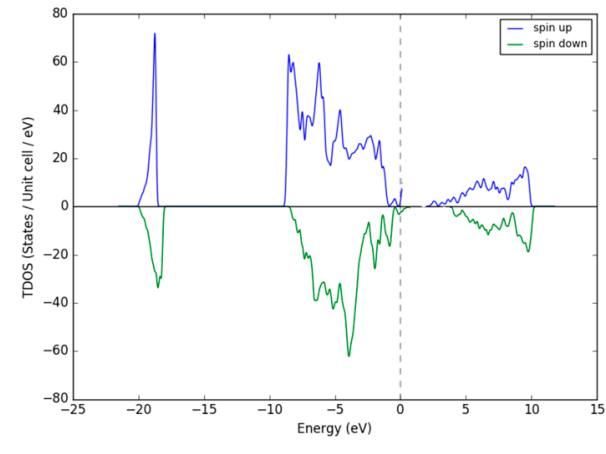

(b)

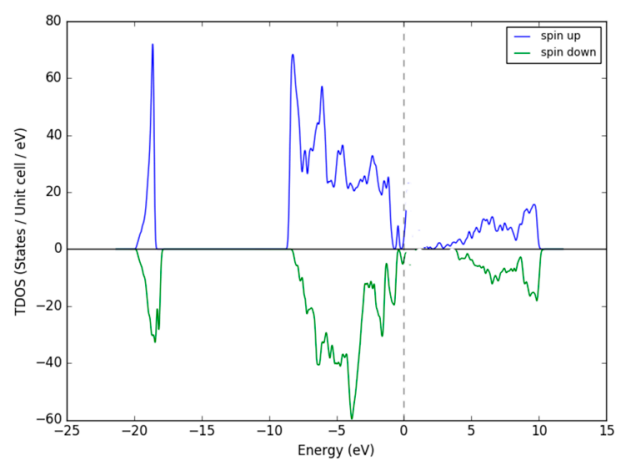

(d)

Figure 4. Densityof States for Pd- doped $\mathrm{NiO}$ (a) 15\%, (b) 18\%, (c) 21\%, and (d) $25 \% \mathrm{Pd}$.

\subsection{Density of States (DOS)—Pt as Dopant Occupying Interstitial Sites inNiO}

Density of States for various \% doping of Pt in $\mathrm{NiO}$ is shown in Figure 5a-d. A band gap of $2.5 \mathrm{eV}$ is observed for $3 \% \mathrm{Pt}^{2+}$ doping. It can be observed that, as the doping increases, there is a slight change in the bandgap of Pt-doped $\mathrm{NiO}$ upto $12 \%$ doping. Due to the large size of $\mathrm{Pt}$ atom, there is some amount of distortion in the lattice arrangement resulting in a dominant $\mathrm{Pt}^{2+}$ vacancy occupying the previously held $\mathrm{Ni}^{2+}$ in the cubic lattice.

For higher doping percentage of $\mathrm{Pt}$ in $\mathrm{NiO}$, there is a further decrease in the bandgap of $\mathrm{Pt}$ doped $\mathrm{NiO}$ from $2.5 \mathrm{eV}$ to $2.0 \mathrm{eV}$, as shown in Figure $6 \mathrm{a}-\mathrm{d}$. This arises from the $\mathrm{Pd}^{2+}$ substituting $\mathrm{Ni}^{2+}$ sites resulting in an increase in the lattice constant and overall volume of the cubic cell. Table 5 summarizes the bandgap versus \% doping in the Pt-NiO system. 


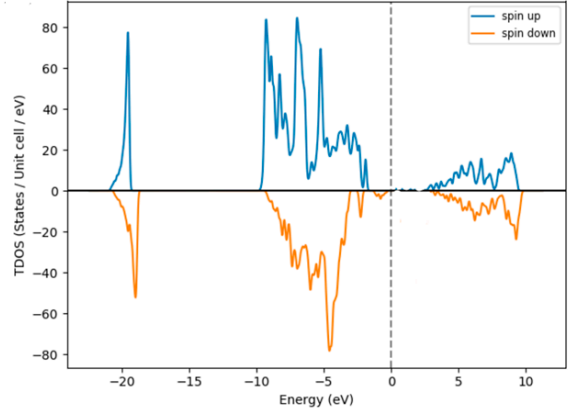

(a)

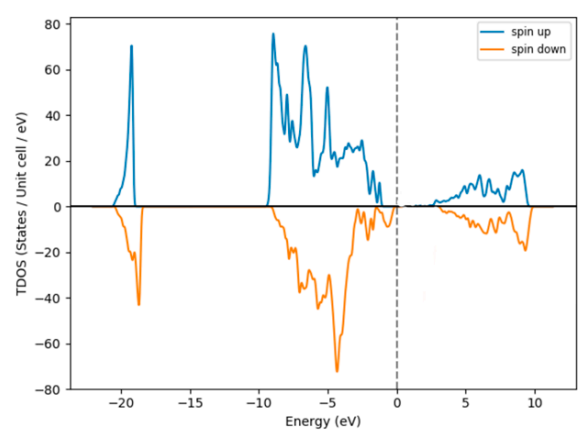

(c)

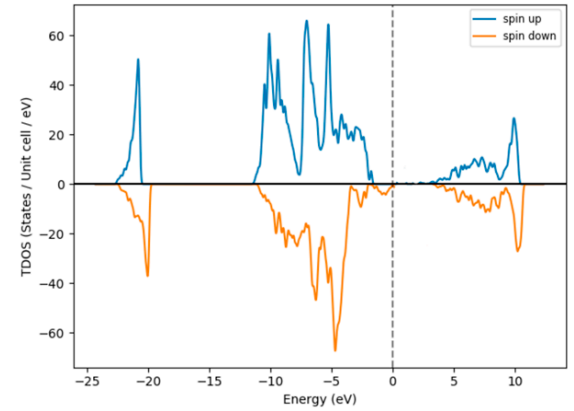

(b)

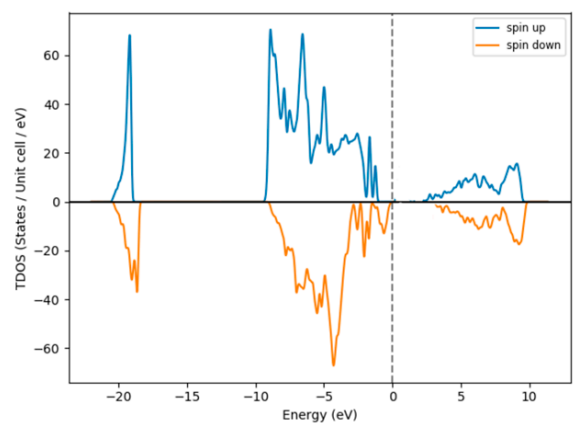

(d)

Figure 5. Density of States for Pt- doped $\mathrm{NiO}$ (a) 3\% Pt, (b) $6 \% \mathrm{Pt}$, (c) $9 \% \mathrm{Pt}$, and (d) $12 \% \mathrm{Pt}$.

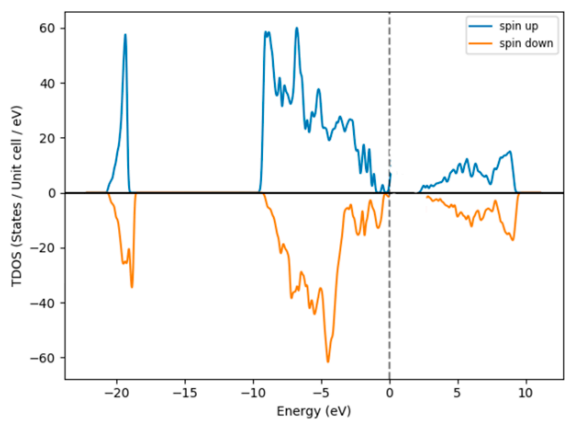

(a)

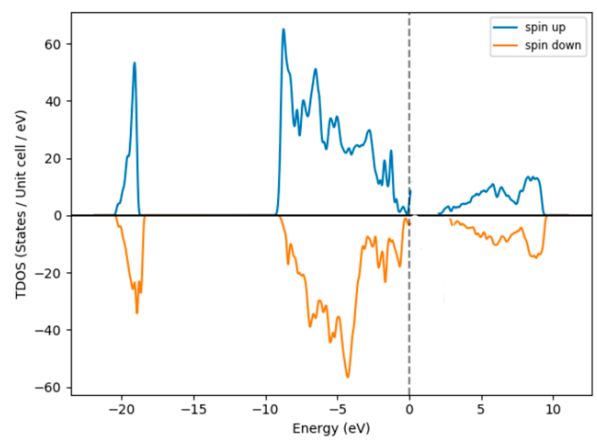

(c)

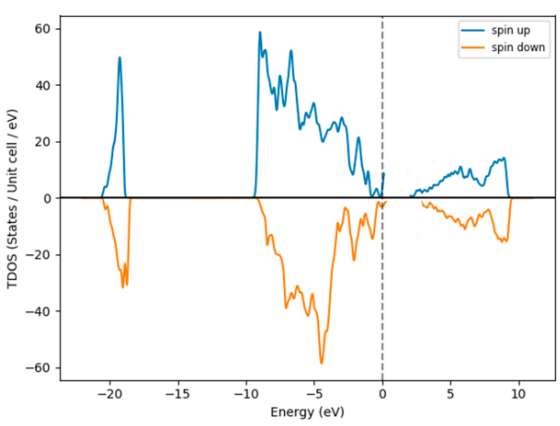

(b)

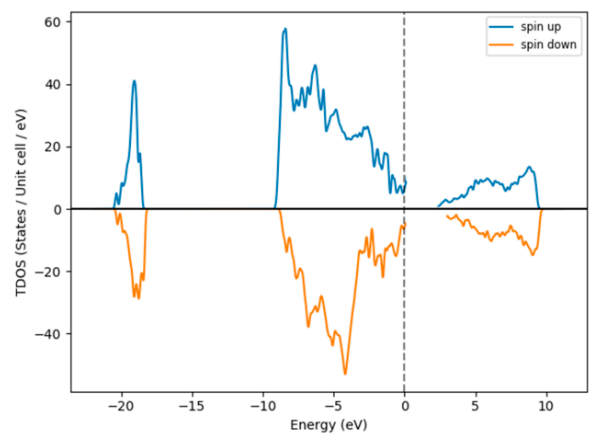

(d)

Figure 6. Density of States for Pt- doped $\mathrm{NiO}$ (a) 15\%, (b) $18 \%$, (c) $21 \%$, and (d) $25 \% \mathrm{Pt}$. 
Table 5. Bandgap of Pt-doped $\mathrm{NiO}$ with respect to \% doping.

\begin{tabular}{ccccccccc}
\hline \% Pt doping & 3 & 6 & 9 & 12 & 15 & 18 & 21 & 25 \\
\hline Bandgap (eV) & $2.50 \pm 0.02$ & $2.40 \pm 0.04$ & $2.40 \pm 0.04$ & $2.25 \pm 0.05$ & $2.15 \pm 0.06$ & $2.10 \pm 0.03$ & $2.0 \pm 0.01$ & $2.0 \pm 0.01$ \\
\hline
\end{tabular}

\section{Conclusions}

Bandgap calculations have been performed on nonstoichiometric $\mathrm{NiO}$ with excess native defects and it is observed that there is a slight increase in the bandgap of NiO. This study also validates that O-rich $\mathrm{NiO}$ is p-type in nature; whereas, Ni-rich $\mathrm{NiO}$ is n-type. Also, doping NiOwith nickel family elements i.e., $\mathrm{Pd}$ and $\mathrm{Pt}$ by varying the doping concentration from $0-25 \%$ is studied. It is observed that there is a decrease in bandgap from $3.8 \mathrm{eV}$ for pure $\mathrm{NiO}$ to $2.5 \mathrm{eV}$ for $25 \% \mathrm{Pd}$ doping. Similarly, there is a decrease in bandgap to $2 \mathrm{eV}$ for $25 \% \mathrm{Pt}$ doping. The density of state calculations suggests that both $\mathrm{Pd}$-and Pt-doped $\mathrm{NiO}$ are p-type in nature.

Author Contributions: S.I. conceptualized, conceived and formally analyzed the computational study; V.B. and F.M. curated the data; S.I. and V.B. validated and drafted the original manuscript; F.M contributed resources; S.I., V.B. and F.M. reviewed and edited the paper.

Funding: This research received no external funding

Acknowledgments: The authors like to thank the facilities in the College of Engineering and the College of Physics and Astronomy at the University of Toledo to carry out this work.

Conflicts of Interest: The authors declare no conflict of interest.

\section{References}

1. Dudarev, S.L.; Botton, G.A.; Savrasov, S.Y.; Humphreys, C.J.; Sutton, A.P. Electron-energy-loss spectra and the structural stability of nickel oxide:An LSDA+U study. Phys. Rev. B 1998, 57, 1505-1509. [CrossRef]

2. Mott, N.F.; Peierls, R. Discussion on the paper by de Boer and Verwey. Proc. Phys. Soc. 1937, 49, 72-73. [CrossRef]

3. Davoli, I.; Marcelli, A.; Bianconi, A.; Tomellini, M.; Fanfoni, M. Multi-electron configurations in the X-ray absorption near-edge structure of $\mathrm{NiO}$ at the oxygen $\mathrm{K}$ threshold. Phys. Rev. B 1986, 33, 2979-2982. [CrossRef]

4. Tomellini, M.; Gozzi, D.; Bianconi, A.; Davoli, I. Local structure of nickel oxide grown at high temperatures in ceramic electrolyte cells. J. Chem. Soc. Faraday Trans. 1987, 83, 289-298. [CrossRef]

5. Bengone, O.; Alouani, M.; Blöchl, P.; Hugel, J. Implementation of the projector augmented-wave LDA+U method: Application to the electronic structure of NiO. Phys. Rev. B 2000, 62, 16392-16401. [CrossRef]

6. Ferrari, A.M.; Ferrero, M.; Pisani, C. An ab Initio Periodic Study of NiO Supported at the Pd(100) Surface. Part 2: The Nonstoichiometric $\mathrm{Ni}_{3} \mathrm{O}_{4}$ Phase. J. Phys. Chem. B 2006, 110, 7918-7927. [CrossRef]

7. Yi, J.B.; Ding, J.; Feng, Y.P.; Peng, G.W.; Chow, G.M.; Kawazoe, Y.; Liu, B.H.; Yin, J.H.; Thongmee, S. Size-dependent magnetism and spin-glass behavior of amorphous $\mathrm{NiO}$ bulk, clusters, and nanocrystals: Experiments and first-principles calculations. Phys. Rev. B 2007, 76, 224402. [CrossRef]

8. Zhang, W.-B.; Yu, N.; Yu, W.-Y.; Tang, B.-Y. Stability and magnetism of vacancy in NiO: A GGA+U study. Eur. Phys. J. B 2008, 64, 153-158. [CrossRef]

9. Park, S.; Ahn, H.-S.; Lee, C.-K.; Kim, H.; Jin, H.; Lee, H.-S.; Seo, S.; Yu, J.; Han, S. Interaction and ordering of vacancy defects in NiO. Phys. Rev. B 2008, 77, 134103. [CrossRef]

10. Rodriguez, J.A.; Hanson, J.C.; Frenkel, A.I.; Kim, J.Y.; Pérez, M. Experimental and Theoretical Studies on the Reaction of $\mathrm{H}_{2}$ with NiO: Role of $\mathrm{O}$ Vacancies and Mechanism for Oxide Reduction. J. Am. Chem. Soc. 2001, 124, 346-354. [CrossRef]

11. Ferrari, A.M.; Pisani, C.; Cinquini, F.; Giordano, L.; Pacchioni, G. Cationic and anionic vacancies on the $\mathrm{NiO}(100)$ surface: $\mathrm{DFT}+\mathrm{U}$ and hybrid functional density functional theory calculations. J. Chem. Phys. 2007, 127, 174711. [CrossRef] [PubMed]

12. Manders, J.R.; Tsang, S.-W.; Hartel, M.J.; Lai, T.-H.; Chen, S.; Amb, C.M.; Reynolds, J.R.; So, F. Solution-Processed Nickel Oxide Hole Transport Layers in High Efficiency Polymer Photovoltaic Cells. Adv. Funct. Mater. 2013, 23, 2993-3001. [CrossRef] 
13. Chen, S.C.; Kuo, T.Y.; Sun, T.H. Microstructures, electrical and optical properties of non-stoichiometric p-type nickel oxide films by radio frequency reactive sputtering. Surf. Coat. Technol. 2010, 205, S236-S240. [CrossRef]

14. Sato, H.; Minami, T.; Takata, S.; Yamada, T. Transparent conducting p-type NiO thin films prepared by magnetron sputtering. Thin Solid Films 1993, 236, 27-31. [CrossRef]

15. Chen, H.-L.; Lu, Y.-M.; Hwang, W.-S. Characterization of sputtered NiO thin films. Surf. Coat. Technol. 2005, 198, 138-142. [CrossRef]

16. Reddy, Y.A.K. Influence of Growth Temperature on the Properties of DC Reactive Magnetron Sputtered NiO Thin Films. Int. J. Curr. Eng. Technol. 2013, 2, 351-357. [CrossRef]

17. Subramanian, B.; Ibrahim, M.M.; Murali, K.R.; Vidhya, V.S.; Sanjeeviraja, C.; Jayachandran, M. Structural, optoelectronic and electrochemical properties of nickel oxide films. J. Mater. Sci. Mater. Electron. 2009, 20, 953-957. [CrossRef]

18. Agrawal, A.; Habibi, H.R.; Agrawal, R.K.; Cronin, J.P.; Roberts, D.M.; Caron-Popowich, R.; Lampert, C.M. Effect of deposition pressure on the microstructure and electrochromic properties of electron-beam-evaporated nickel oxide films. Thin Solid Films 1992, 221, 239-253. [CrossRef]

19. Yeh, W.; Matsumura, M. Chemical Vapor Deposition of Nickel Oxide Films from Bis- $\pi$-Cyclopentadienyl-Nickel. Jpn. J. Appl. Phys. 1997, 36, 6884-6887. [CrossRef]

20. Raut, B.T.; Pawar, S.G.; Chougule, M.A.; Sen, S.; Patil, V.B. New process for synthesis of nickel oxide thin films and their characterization. J. Alloys Compd. 2011, 509, 9065-9070. [CrossRef]

21. Guo, W.; Hui, K.N.; Hui, K.S. High conductivity nickel oxide thin films by a facile sol-gel method. Mater. Lett. 2013, 92, 291-295. [CrossRef]

22. Tanaka, M.; Mukai, M.; Fujimori, Y.; Kondoh, M.; Tasaka, Y.; Baba, H.; Usami, S. Transition metal oxide films prepared by pulsed laser deposition for atomic beam detection. Thin Solid Films 1996, 281, 453-456. [CrossRef]

23. Reguig, B.A.; Khelil, A.; Cattin, L.; Morsli, M.; Bernède, J.C. Properties of NiO thin films deposited by intermittent spray pyrolysis process. Appl. Surf. Sci. 2007, 253, 4330-4334. [CrossRef]

24. Kang, J.-K.; Rhee, S.-W. Chemical vapor deposition of nickel oxide films from Ni(C5H5)2/O2. Thin Solid Films 2001, 391, 57-61. [CrossRef]

25. Liu, H.; Zheng, W.; Yan, X.; Feng, B. Studies on electrochromic properties of nickel oxide thin films prepared by reactive sputtering. J. Alloys Compd. 2008, 462, 356-361. [CrossRef]

26. Brückner, W.; Kaltofen, R.; Thomas, J.; Hecker, M.; Uhlemann, M.; Oswald, S.; Elefant, D.; Schneider, C.M. Stress development in sputtered $\mathrm{NiO}$ thin films during heat treatment. J. Appl. Phys. 2003, 94, 4853. [CrossRef]

27. Kuzmin, A.; Purans, J.; Rodionov, A. X-ray absorption spectroscopy study of the Ni K edge in magnetron-sputtered nickel oxide thin films. J. Phys. Condens. Matter 1997, 9, 6979-6993. [CrossRef]

28. Itapu, S.; Khan, K.; Georgiev, D.G. Effect of UV Laser Irradiation on the properties of NiO films and ZnO/NiO Heterostructures. MRS Adv. 2016, 1, 293-298. [CrossRef]

29. Itapu, S.; Georgiev, D.G.; Uprety, P.; Podraza, N.J. Modification of reactively sputtered $\mathrm{NiO}_{x}$ thin films by pulsed UV laser irradiation. Phys. Status Solidi 2017, 214, 1600414. [CrossRef]

30. He, J.H.; Yuan, S.L.; Yin, Y.S.; Tian, Z.M.; Li, P.; Wang, Y.Q.; Liu, K.L.; Wang, C.H. Exchange bias and the origin of room-temperature ferromagnetism in Fe-doped NiO bulk samples. J. Appl. Phys. 2008, 103, 23906. [CrossRef]

31. Han, D.; Jing, X.; Wang, J.; Yang, P.; Song, D.; Liu, J. Porous lanthanum doped NiO microspheres for supercapacitor application. J. Electroanal. Chem. 2012, 682, 37-44. [CrossRef]

32. Li, J.-C.; Hou, X.-Y.; Cao, Q. Effect of Cu doping on the resistive switching of NiO thin films. J. Appl. Phys. 2014, 115, 164507. [CrossRef]

33. Dutta, T.; Gupta, P.; Gupta, A.; Narayan, J. Effect of Li doping in NiO thin films on its transparent and conducting properties and its application in heteroepitaxial p-n junctions. J. Appl. Phys. 2010, 108, 83715. [CrossRef]

34. Li, G.; Li, L.; Jiang, D.; Shi, J. Design of a meso-structured Pd/NiO catalyst for highly efficient low temperature CO oxidation under ambient conditions. RSC Adv. 2015, 5, 40352-40357. [CrossRef]

35. Sambi, M.; Sensolo, R.; Rizzi, G.A.; Petukhov, M.; Granozzi, G. Growth of NiO ultrathin films on Pd(100) by post-oxidation of Ni films: The effect of pre-adsorbed oxygen. Surf. Sci. 2003, 537, 36-54. [CrossRef] 
36. Zou, X.; Rui, Z.; Ji, H. Core-Shell NiO@PdO Nanoparticles Supported on Alumina as an Advanced Catalyst for Methane Oxidation. ACS Catal. 2017, 7, 1615-1625. [CrossRef]

37. Huang, S.; Zhu, X.; Cheng, B.; Yu, J.; Jiang, C. Flexible nickel foam decorated with Pt/NiO nanoflakes with oxygen vacancies for enhanced catalytic formaldehyde oxidation at room temperature. Environ. Sci. Nano 2017, 4, 2215-2224. [CrossRef]

38. Nie, L.; Meng, A.; Teng, F.; Cheng, B. Hierarchically macro-mesoporous flowerlike Pt/NiO composite microspheres for efficient formaldehyde oxidation at room temperature. RSC Adv. 2015, 5, 83997-84003. [CrossRef]

39. Qi, L.; Cheng, B.; Ho, W.; Liu, G.; Yu, J. Hierarchical Pt/NiO Hollow Microspheres with Enhanced Catalytic Performance. ChemNanoMat 2015, 1, 58-67. [CrossRef]

40. Walker, M.; Parkinson, C.R.; Draxler, M.; Brown, M.G.; Mcconville, C.F. Initial growth of platinum on oxygen-covered $\mathrm{Ni}(110)$ surfaces. Surf. Sci. 2006, 600, 3327-3336. [CrossRef]

41. Kresse, G.; Furthmüller, J. Efficient iterative schemes for $a b$ initio total-energy calculations using a plane-wave basis set. Phys. Rev. B 1996, 54, 11169-11186. [CrossRef]

42. Av, G.K.; Furthmiiller, J. Efficiency of ab-initio total energy calculations for metals and semiconductors using a plane-wave basis set. Comput. Mater. Sci. 1996, 6, 15-50.

43. Kresse, G.; Hafner, J. Norm-conserving and ultrasoft pseudopotentials for first-row and transition elements. J. Phys. Condens. Matter. 1994, 6, 8245-8257. [CrossRef]

44. Methfessel, M.; Paxton, A.T. High-precision sampling for Brillouin-zone integration in metals. Phys. Rev. $B$ 1989, 40, 3616-3621. [CrossRef]

45. Hahn, T. (Ed.) International Tables for Crystallography Volume A: Space-Group Symmetry, 5th ed.; Springer: Amsterdam, The Netherlands, 2002; p. 688.

46. Bruska, M.K.; Czekaj, I.; Delley, B.; Mantzaras, J.; Wokaun, A. Electronic structure and oxygen vacancies in PdO and ZnO: Validation of DFT models. Phys. Chem. Chem. Phys. 2011, 13, 15947-15954. [CrossRef] [PubMed]

47. Jacob, T. Theoretical investigations on the potential-induced formation of Pt-oxide surfaces. J. Electroanal. Anal. Chem. 2007, 607, 158-166. [CrossRef] 